\title{
Research on Cultural Factors in College Chinese-English Translation Teaching
}

\author{
Minfang Wang \\ Xijing University, Xi'an, Shaanxi, 710123
}

Keywords: Chinese-English Translation, Cultural Factors, Translation Teaching

\begin{abstract}
With the continuous implementation and deepening of China's opening-up policy, English, as a more commonly used communication and communication language, has gradually attracted people's attention and attention. College English translation is an important subject in college English teaching. College English translation teaching should pay attention to the influence of cultural factors on education and teaching quality, strengthen the excavation and mastery of cultural factors, and actively understand the relevant historical and cultural contents. To a large extent, improve the quality of college English translation of learning, improve college students' cultural awareness and promote the all-round development of students. This article analyzes and expounds the cultural factors in college English translation in our country, and points out the present situation of cultural awareness in college English translation and puts forward some reasonable suggestions for its development. College English translation is an important subject in the school. In the process of college English translation teaching, it is necessary to pay more attention to the influence of cultural factors on the quality of English teaching and to fully understand and master the cultural factors and connotation. This article will mainly focus on the cultural factors in college English translation.
\end{abstract}

\section{Introduction}

Translation, ie, "the conversion of the same or similar meaning between a particular symbol in one language culture and a particular symbol in another language culture." The purpose of learning a language is to communicate with others. Such communication, whether verbal or nonverbal, is culturally constrained. Therefore, in the process of translation, it is a process of conversion from source language to target language. Two languages and cultures must be deeply understood and mastered. At present, there are two problems in college English translation teaching: one is the disagreement between teaching contents and students' actual communication skills; and the other is that most non-English major students do not pay attention to the improvement of translation ability at this stage, even paying attention to the translation ability Improve, but also do not realize the important role of cultural differences in translation. Therefore, in English translation teaching, teachers should adopt effective teaching methods to introduce cultural factors into the classroom so that students can understand the important role of cultural information.

\section{The Present Situation of College Students' English Translation Studies}

After observing the practice of college English teaching, a large number of non-English major students take a lot of time and energy in learning English, taking words, phrases and grammar in order to pass CET-4. However, learning a language means experiencing the country's history and culture. In the process of translation, different ways of thinking determine different expressions, which is especially evident. However, at this stage, students' translation skills are generally weak. As can be seen from the questions and exams in the classroom, many students do not attach importance to the improvement of their abilities in this area. Fourth grade examinations of new questions, translation from the original five minutes to fifteen minutes, the syllabus stressed the importance of Chinese culture, some students began to gradually focus on the combination of translation and culture. This shows that if students fail to improve their translation skills, their long-term development has been greatly hindered. 


\section{English and Chinese language cultural differences}

The differences between eastern and western history and cultural backgrounds lead to great differences in the meanings of English and Chinese language words. The meaning of a word in a specific culture may have completely different or even opposite connotations in another language and culture. For example, dragons represent aristocrats in China and dragon represents viciousness. Dogs have curse meanings in China, such as "doglegs" and "jittering". Dogs in the eyes of the West represent loyalty, for example, "Love me , love my dog ". This is the difference in terms of meaning between two different historical and cultural backgrounds. Some idioms are the same, for example: "stupid like a pig" translated into English as stupid as agoose, goose geese as stupid symbols; "headless flies" translated as as blind as a bat, and bat said There is no sense of things, which shows the difference between the two cultures.

Some words in the source language are translated into the target language, although the concept of meaning is consistent with the vocabulary, but the meaning of the source language has been part of the missing. Such as "well-thought." If you literally translate it verbatim into English, you have: He has mature bam-boo in his breast. However, such a translation has lost its implicit metaphor. Therefore, idiom translations such as this should first translate the metaphorical meaning as the goal, since there is no such statement in foreign cultures that is easily misleading and should be translated in a free-speech manner as: He has a wel1-thought -out plan in his mind. Thus, the same vocabulary in two different cultural backgrounds have different cultural connotations, in the translation should fully understand its cultural information.

The differences between Chinese and English in the historical and cultural backgrounds determine the differences in structure and content between the two languages. The Chinese nation is a nation with a long history and a rich culture. In our daily language expressions, we will modify attributive or adverbial expressions before the target words. However, contrary to the Chinese way of expression, people in English-speaking countries are more inclined to express their main meaning directly, and later supplement or explain the whole sentence. For example: I am not happy to hear that bad news. Well, the sentence is in English: "I was unhappy when I heard the bad news." If I translate it to "I am unhappy, when I hear that bad news," it does not seem smooth and does not fit The logical order of Chinese. This example fully demonstrates that in the translation must pay attention to the structural differences in the language.

\section{Western and Western cultural differences and the cultural Factors in translation}

There are many differences between the cultures of China and western countries, and the more important one is the traditional festival culture. Ancient China has always been a country that values agriculture because the seasons and weather have an important role in ancient agricultural production Therefore, most of the traditional festivals established to celebrate the bumper harvest are related to the seasons such as "the Ching Ming Festival" is closely linked with agricultural activities such as planting and harvesting, and "Ching Ming" is also one of the 24 solar terms in China. In western countries, the center of social culture is religion. Therefore, many festivals in the West are closely linked with religions (such as Christianity). For example, Christmas is the day Christians honor the birth of Jesus. Easter is a Christian memorial As a festival of Jesus' resurrection, there are also different customs in the Western and Chinese festivals. In Chinese festivals, Chinese often give polite replies to gifts sent by others, which are generally accepted without helplessness Face to face open, if the face opened and over-happy performance may also fall a "greedy" name The Westerners are generally glad to accept gifts from other people and openly praising them in person. There are also differences in terms of auspiciousness and taboo words in Chinese and English, for example, the Chinese taboo the number "4" "Death" homophonic, so often there is no fourth floor in the hospital inpatient department. The western society is not sensitive to the number "4", but the number "13" need to be circumvented, mainly from Christian "last supper" In the thirteenth "Judah" betrayed Jesus.

The spirit of collective cooperation is the mainstream value of the Chinese culture, and the 
contemporary advocates the spirit of collectivism. This spirit advocates that the interests of the group are higher than those of the individual, and the personal interests are not allowed to override the collective interests. This collective spirit of cooperation is culturally It is characterized by the group characteristics of culture, which emphasizes the family-friends relationship and considers the family as the constituent cells of the society. While from the Renaissance, the mainstream values in the western countries are mainly manifested as humanism, advocating the individual interest as the center and advocating individualism Supremacy, advocating freedom and self-expression. With the influence of Western mainstream values, Western culture is more independent and equal freedom, for example, English cousin said the parents of siblings children, while in Chinese the same Kinship can be expressed as "cousin, cousin, cousin, cousin, cousin, cousin, cousin, cousin."

Different religious beliefs have different effects on cultural development and development. In China, Confucianism was regarded as orthodox thought in feudal history, it acknowledged heaven and destiny, and believed that heaven-dominated human destiny, but heaven and destiny They are all abstract powers that do not specifically refer to a certain god. It can be a god or a Goddess of Mercy, believing that good faith in God can bring good fortune. Therefore, in Chinese culture there will be " Contrary to "life and death, wealth in the sky," "optimistic life." In Western countries, Christianity as a major religious belief, that all things in the world are derived from God, God created and dominated the entire world, people must absolutely Obey God, or you will be punished by God, the corresponding appeared in English "God helps those who help themselves" "Manproposes, God disposes" and so on. In addition , The difference of religious culture also affects the different ways of thinking between China and the West. Chinese people use traditional Confucianism Family culture as the background, focusing on the whole and the image, while the Westerners who are based on the Christian culture pay more attention to the thinking and analysis of the logic problems.For example, the use of conjunctions in English is very rigorous and rich, can clearly show the Westerners Logical thinking, as used in the sentence "If winter comes, can spring be farbehind?", Strongly implies the hypothesis that the logic of Westerners.

Many words that are expressions of meaning in the English language are unimportant in the Chinese language, such as the English word "brother" meaning "brother" and "brother" in the Chinese language, but " Brother "or" brother. "Like cry, which means" cry, shout, call "in English, net means" net, account ", bank means" bank, bank "and kids say" "Etc. Students often do not pay too much attention when they encounter this situation, often translating" cry "into" shout "and" brother "only translating into" younger brother. "

For example, a new international economic order translates the sentence into "a new international economic order," and according to our Chinese language order, it is more reasonable to translate it into a "new international economic order." There are many similar examples For example, a small round wooden table, the Chinese will translate it into a wooden round table; big white stone building, free translation for the white stone building; ancient Chinese gentlemen, free translation of ancient Chinese history, and so on.

The precipitation of social heritage formed in a particular historical development process is history. Different ethnic groups have largely different historical development processes. There are also many differences in their cultural backgrounds, so that if there is a deep understanding of the history and culture of other ethnic groups, Every ethnic characteristic of history and culture tends to be biased in terms of understanding, while historical and cultural knowledge is often not valued or neglected in college English translation teaching, and these neglected parts are indispensable in English translation Sometimes the similar words in both Chinese and English express different meanings while the seemingly different terms express the same words, say "to meet one's Waterloo" In the nineteenth century, the French emperor Napoleon suffered a fiasco in the battle against the Belgian coalition forces of other countries slaughtered in the Belgian town of Waterloo. In our Chinese language, there is a similar term "walking in the city of wheat," referring to China History of the Three Kingdoms period General Shu Yu Guanghui defeated the story of a retreat to the city of Mai. Two idioms But from different historical events, but its meaning is the same .For example, Shaanxi People's Publishing House once published the "Chinese-English translation tutorial" a book, 
which introduces the historical and cultural Tang Dynasty Such a sentence: "He grew up to study Buddhism from the monks, the prestigious Western Regions." "Western" in the book was translated into "West Region", literal translation of the western region. However, in fact, the Western Regions in the Tang Dynasty refer to the vast territory of the West, including the present and future Xinjiang and Central Asia. The phrase "West China, West China" can not be properly expressed In order to enable foreigners to have a more accurate understanding of the "Western Regions", some additional supplementary explanations are needed.

\section{Conclusion}

Translation involves the proficiency of the relevant language, the understanding of culture and the precipitation of knowledge and many other factors, focusing on cultivating students 'cultural literacy and cultural awareness in college English translation teaching, so as to improve students' translation skills. This is a major issue The long-term measures can really enhance the students' translation skills, enhance their initiative in learning and promote the integration and steady development of China's education.

\section{References}

[1] Wei Mengfen. Discussion on Cultural Introduction in College English Translation Teaching [J]. Journal of Huaihai Institute of Technology (Social Science Edition), 2010, 17 (06): 52-53.

[2] HU Fang. On Cultural Factors in College English Translation Teaching [J]. Literature and Education (in), 2013, 10 (09): 85-86.

[3] Zhang Qi. Cross-cultural guidance in college English translation teaching [J]. Science Education (middle), 2010, 2 (01): 36-38.

[4] Deng Hongchun. Cross-cultural perspective of college English translation teaching [J]. Shanxi Radio and TV University, 2011 (06): 64-67.

[5] Yuan Dao. My English translation of college English [J] education and occupation, 2004 (20) 